\title{
Introduction of daily minimum and maximum temperature change signals in the Shikoku region using the statistical downscaling method by GCMs
}

\author{
Kenichi Tatsumi ${ }^{1}$, Tsutao Oizumi ${ }^{2}$ and Yosuke Yamashiki ${ }^{3}$ \\ ${ }^{1}$ Department of Environmental and Agricultural Engineering, Tokyo University of Agriculture \& Technology, Japan \\ ${ }^{2} J a p a n$ Agency for Marine-Earth Science and Technology, Research Institute for Global Change, Japan \\ ${ }^{3}$ Graduate School of Advanced Integrated Studies in Human Survivability, Kyoto University, Japan
}

\begin{abstract}
:
Impacts of climate change may depend more on changes in mean daily minimum temperature $\left(\mathrm{T}_{\min }\right)$ or maximum temperature $\left(\mathrm{T}_{\max }\right)$ than on average temperature $\left(\mathrm{T}_{\mathrm{avg}}\right)$. In this study, we apply a statistical downscaling model (SDSM) for estimating the average length of spells with temperature values greater than $\mathrm{T}_{\max }=30^{\circ} \mathrm{C}\left(\right.$ ALS30), $\mathrm{T}_{\max }$, and diurnal temperature range (DTR) for the present period (1961-1990) and the future period (2071-2099) climate conditions. The outputs of two GCMS (HadCM3 and CGCM3) are used to show the potential applicability of SDSM. Scenarios A2, $\mathrm{A} 1 \mathrm{~B}$ and $\mathrm{B} 2$ are used by the SDSM to construct climate scenario information over the Shikoku region. The results showed that: (1) The SDSM model is able to capture the major part of the temperature change signals, with a plausible climatic regime for higher warming; (2) From June to August, the average DTR changes in northern Shikoku would be positive; but in southern Shikoku, the changes would be negative under A2, A1B, and $\mathrm{B} 2$ scenarios using HadCM3 and CGCM3. The most important finding is that the DTR trend will be different at the local scale and these results highlight the importance of separately considering projections for $T_{\min }$ and $T_{\max }$, when evaluating climate change impact for hydrological and agricultural applications.
\end{abstract}

KEYWORDS climate change; maximum temperature;
diurnal temperature range; statistical
downscaling model; Shikoku

\section{INTRODUCTION}

It has been pointed out by the IPCC (2007) that the global surface temperature has increased by $0.74^{\circ} \mathrm{C} \pm 0.18^{\circ} \mathrm{C}$ in the last century (1906-2005), and the frequency of heavy rain has increased in many land areas, even when total precipitation has decreased. These climate changes tend to most severely affect the mid- and high-latitudes of the Northern Hemisphere, which in turn can be expected to affect ecological, social and economical systems, industrial and agricultural water supplies, human health, and other factors. Global warming has the potential to cause higher evaporation rates and transport larger amounts of water vapor into the atmosphere, possibly resulting in the acceleration of global hydrological and agricultural cycles. Thus, the impacts of global warming on the agricultural cycle have

Correspondence to: Kenichi Tatsumi, Department of Environmental and Agricultural Engineering, Tokyo University of Agriculture \& Technology, 3-5-8 Saiwai-cho, Fuchu, Tokyo 183-8509, Japan. E-mail: ktatsumi@cc.tuat.ac.jp (C2013, Japan Society of Hydrology and Water Resources. become the focus of large-scale investigations (Masutomi et al., 2009; Tan and Shibasaki, 2003; Tatsumi et al., 2011). In addition, global warming may have a large effect on the land productivity of individual crops and overall crop production. In southern Japan, there are many correlations between the higher temperature in the period between June to August, and an outbreak of cracked, broken, dead, and immature rice grains (Nagata et al., 2004).

Studies on changes in extreme temperature events such as frost days or heat waves have been previously carried out by several researchers (Hegerl et al., 2004; Tebaldi et al., 2006; Lobell et al., 2007). Their focus primarily reflects the importance of both average daily temperatures and extreme events in determining climate change impacts (Easterling et al., 2000). Thus, the agricultural impacts are more directly related to changes in $\mathrm{T}_{\min }$ or $\mathrm{T}_{\max }$ rather than $\mathrm{T}_{\text {avg }}$ or extreme events. For example, quantities such as accumulated temperatures and growing degree days, which are widely used in the crop models, are influenced differently by $\mathrm{T}_{\min }$ and $\mathrm{T}_{\max }$ (Wilkens and Singh, 2001; Tatsumi et al., 2012). In addition, changes in evapotranspiration and photosynthetic rates are likely to be more affected by $\mathrm{T}_{\max }$ than $\mathrm{T}_{\min }$ (Dhakhwa and Campbell, 1998). Deterioration and low yield of rice are often caused by high temperatures $\left(>30^{\circ} \mathrm{C}\right)$ (Kondo et al., 2005). Moreover, their results using the GCM (General Circulation Models) outputs are useful in understanding climate change uncertainty and the impacts of global warming on hydrology and agriculture.

Downscaling methods can be broadly divided into two classes: dynamical downscaling (DD) and statistical downscaling (SD). In dynamical downscaling, the GCM outputs are used as boundary and initial conditions used to drive a Regional Climate Model (RCM), such as the JapanMeteorological-Agency Non-Hydrostatic Model (JMANHM) (Saito et al., 2006), or the Weather Research Forecasting (WRF) model (Skamarock et al., 2005). This method responds in physically consistent ways to different external forcing. DD has a higher computational cost, and the results depend strongly on the boundary conditions provided by the GCM. In comparison, SD produces localor station-scale meteorological time series by calculating the appropriate statistical or empirical relationships with predictor variables. This method does not require high levels of computational resources, and it has been widely used in climate change studies and uncertainty assessments. However, SD requires historical observational data of sufficient length, typically 30 years (Wilby et al., 2002). Studies on statistical downscaling methods have been carried

Received 10 April, 2013 Accepted 4 July, 2013 
out by many researchers (Chen et al., 2006; Hashmi et al., 2011; He et al., 2011; Huang et al., 2011; Iizumi et al., 2012). However, few attempts have been made to reproduce the $\mathrm{T}_{\max }$ and DTR using SDSM in a sub-grid scale (around $1 \mathrm{~km}$ ). The SDSM method may be able to contribute to further improvement of the hydrological and agricultural model. For these reasons our study addresses the Shikoku region of Japan.

In this study, the ability of a SDSM to downscale temperature is investigated with the aim of evaluating simulations of $\mathrm{T}_{\max }$, DTR and ALS30 magnitude, and frequency in order to facilitate agricultural and hydrological resource assessment. Here, we evaluate using SDSM the differences between statistical properties of the present and the future $\mathrm{T}_{\max }, \mathrm{T}_{\min }$ and DTR using the Hadley Centre Coupled Model, version 3 (HadCM3), and the third version of the Canadian Centre for Climate Modelling and Analysis Coupled Global Climate Model (CGCM3).

\section{DATA AND METHODS}

\section{Study site}

The study focuses on the Shikoku region, which is located in the southwestern part of Japan, between about $32.7 \mathrm{~N}$ and $34.6 \mathrm{~N}$, and $132.0 \mathrm{E}$ and $134.8 \mathrm{E}$. The island has a typical sea island climate. Shikoku has notably different characteristics to the north and south of the Shikoku Mountains. The Seto Inland Sea side, to the north, has a warm climate and scanty rainfall. Conversely, the side facing the Pacific Ocean has relatively high temperatures and high precipitation. In this study, the region is divided into two parts separated by the Shikoku Mountains: (a) the northern Shikoku region (red points in Figure 1); and (b) the southern Shikoku region (blue points in Figure 1).

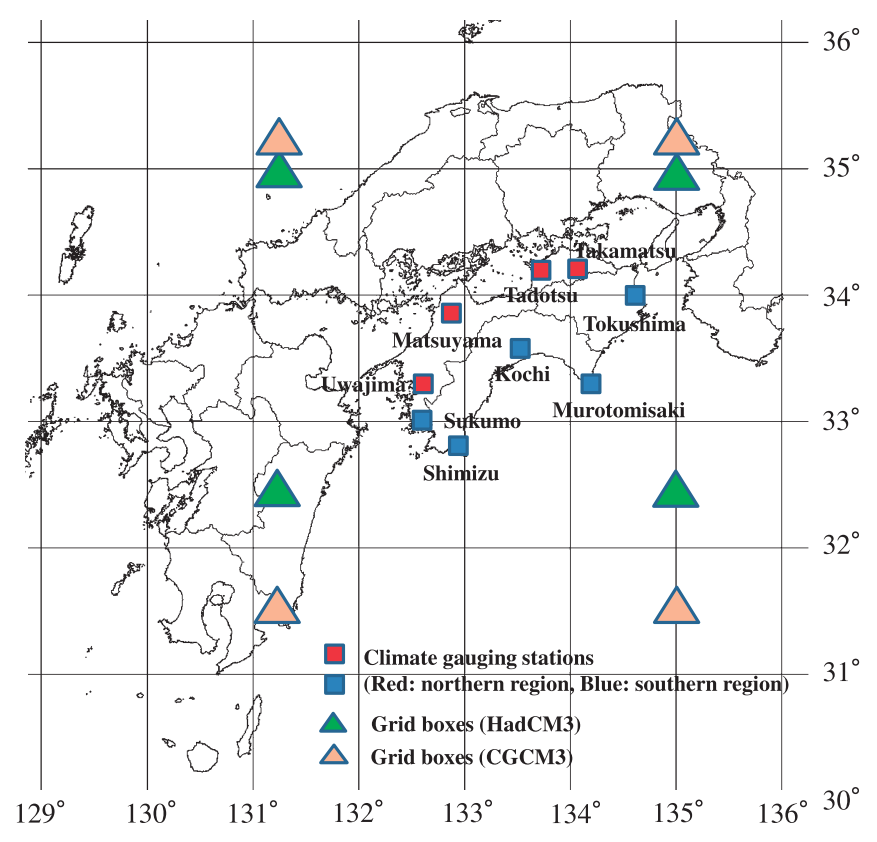

Figure 1. The location of climate gauging stations and HadCM3 and CGCM3 grid boxes in the Shikoku region

\section{Data}

The daily observed $\mathrm{T}_{\min }$ and $\mathrm{T}_{\max }$ data for the period 1961-2000 were collected at a total of nine stations over the Shikoku region (Figure 1), from the Surface Daily observation Point (SDP) data. Large-scale observed atmospheric predictor variables were obtained from the National Centers for Environmental Prediction (NCEP) for reanalysis. This dataset is a daily series for the period 19612000 at a special scale of $2.5^{\circ}$ (lat) $\times 2.5^{\circ}$ (lon), including 26 atmospheric variables including geopotential height at 500 and $850 \mathrm{hPa}$, sea level pressure, near-surface relative humidity, near-surface specific humidity, and $2 \mathrm{~m}$ air temperature, amongst others (Supplement Table SI). The time series data of the atmospheric predictor variables of a grid box closest to the study area were used as predictor variables to develop and test the SDSM model with observed temperature data (1961-2000). At this time, HadCM3 and CGCM3 (DAI CGCM3 Predictors, 2008) multi-models have been officially published and are available as statistical downscaling input by SDSM. The GCMs adopted in this study are the HadCM3 and CGCM3. HadCM3 is a coupled atmosphere-ocean GCM developed at the Hadley Centre, UK (Gordon et al., 2000; Pope et al., 2000). HadCM3 is a grid point model over land with a horizontal resolution of $2.5^{\circ} \times 3.75^{\circ}$ lat-long and 19 levels in the vertical, while the ocean model has a resolution of $1.25^{\circ} \times 1.25^{\circ}$ lat-long. The CGCM3 surface and near-surface variables were defined at a daily scale on a global Gaussian grid of $3.75^{\circ} \times 3.75^{\circ}$ latlong (DAI CGCM3 Predictors, 2008). NCEP data was interpolated in order to adjust its resolution to be the same as both models. Therefore, predictor variables are interpolated from a native regular Gaussian grid to the HadCM3 and CGCM3 regular grid, respectively. The transformed data can be directly downloaded from the internet site: http://www.cccsn.ec.gc.ca/index.php?page= dst-sdi. The HadCM3 and CGCM3 grid boxes selected in the Shikoku region are shown in Figure 1 and Supplement Table SII. Supplement Table SII shows that the coordinates of each station and value in each grid box corresponds to the value over the center of the cell defined over an area. To simulate different climate change scenarios, HadCM3 data under A2 (high greenhouse gas emission scenarios, H3 A2, including the present climate) and B2 (low greenhouse gas emission scenarios, H3 B2, including the present climate), and CGCM3 data under $20^{\text {th }}$ Century Climate in Coupled Models (C3_20C3M), A2 (C3_A2) and A1B scenarios (balanced across energy sources, $\overline{\mathrm{C}} 3$ A1B) established by SRES (IPCC, 2001; 2007), were used with a calibrated model, weather generator and scenario generator. The scenario generator operation produces ensembles of synthetic daily weather series for the potential atmospheric predictor variables supplied by GCMs for the present or future climate experiments.

\section{Statistical downscaling model}

In this study, SDSM version 4.2, which is a decision support tool for the assessment of regional climate change impacts (Wilby et al., 2007), was used to downscale daily $\mathrm{T}_{\min }$ and $\mathrm{T}_{\max }$ for the simulated $\mathrm{T}_{\max }$ and DTR indices in the Shikoku region. SDSM is a multivariate regression method for generating future climate scenarios to assess the 
impact of climate change. It is designed to simulate, through a combination of regressions and weather generators, sequences of daily climatic data for the present and future periods by extracting statistical parameters from observed data series (Supplement Figure S1). The daily data from NCEP and GCMs are used in the construction of current and future daily weather series (Wilby et al., 2002; Wilby and Dawson, 2007). Using the explanatory and objective variables detailed above, present and future daily weather data was developed. The procedure of downscaling is based on the availability of tools and data follows nine discrete processes: (1) Quality control of data and transformation; (2) Selection of appropriate predictor variables for model calibration; (3) Development of a nonlinear regression model by means of a statistical transfer function, using NCEP reanalysis data and the observed values; (4) Calibration of the model using predictors from NCEP and current reproduction; (5) Synthesis of observed data and generation of daily data; (6) Verification of the simulation precision of the model by comparing its results with the observed values (Validation of the model); (7) Development of a daily weather dataset for 1961-2099 for CGCM3 and HadCM3 using the regression model, weather generator, and scenario generator; (8) Analysis of the outputs; and (9) Diagnostic testing and statistical analyses. In order to evaluate the robustness method, statistical tests were carried out on the monthly $\mathrm{T}_{\max }$ and DTR indices. The first 30 years (19611990) are considered for calibrating the regression models. The validation period was 10 years (1991-2000). Some of the SDSM setup parameters for variance inflation and bias correction are adjusted during calibration to obtain a good statistical agreement between the observed and simulated climate variables. The detailed technical information of SDSM can be found in Wilby et al. (2002).

Finally, the daily, monthly, seasonal and annual temperature series under the northern and southern Shikoku region can be constructed by the average value of all stations. The future long-term change in $\mathrm{T}_{\max }$, DTR and ALS30 indices were analyzed for the Shikoku region.

\section{RESULTS}

\section{Calibration and validation of SDSM}

Supplement Figure S2 shows that the overall Coefficients of Determination $\left(R^{2}\right)$ and Standard Errors (SE) of each month during the calibration period have seasonal variation. The visualization interpreted for generated daily data showed that SDSM methods were on the whole doing well. However, the simulation results were better for $\mathrm{T}_{\max }$ than DTR. $R^{2}$ $(0.60)$ of $T_{\max }$ in the south is relatively low in summer. In contrast, SE is larger in winter than in summer (JulySeptember). Gridded data such as reanalysis and GCM that present a large-scale meteorological field is not suited to reproduce the local events, although the data for $\mathrm{T}_{\max }$ and DTR indices is of statistical significance (t-test, $p<0.01$ ). Supplement Figure S3 shows a comparison between the observed and SDSM-estimated $\mathrm{T}_{\max }$ and $\mathrm{T}_{\min }$ in north and south regions of Shikoku during the validation period (19912000). For NCEP, H3_A2 and H3_B2, the maximum and minimum temperatures in autumn tended to be lesser than the observed data, but the reproducibility was very high.
Similarly, for H3_A2, H3_B2 and C3_20C3M, ALS30 was lower than for the observed data, except for winter, and the statistical reproducibility of ALS30 using the explanatory variables from NCEP and GCMs was high (Supplement Figure S4). Likewise, the data obtained by statistical downscaling for the minimum and maximum daily temperature were generally in agreement with the observed data, and the reproducibility was favorable overall (Supplement Figure S5 and Supplement Figure S6).

\section{Downscaling temperature corresponding to future climate change scenario}

The downscaling models have been setup and validated. The next step is to use these models to downscale the future climate change scenario simulated by HadCM3 and CGCM3. The large-scale predictor variables to be used as an input to the downscaling model are derived from GCM simulation outputs. The SDSM tool allows us to generate ensembles of current weather data using observed predictor variables (Wilby et al., 2002). In order to analyze extreme temperature events, we fitted the distribution to more than 50 continuous and discrete distributions (for example, Gaussian, Weibull, Gamma, Pearson, etc.) and calculated the best fitted test statistics for each of the fitted distributions. As a result, the log-normal (three-parameter) distribution was found to be the best fitted. Figure 2 shows the ALS30 of twenty ensemble members for the present and the future using the calibrated regression models. Under the A2 scenario by HadCM3 and CGCM3, ALS30 for the future period increased significantly compared to the present period (t-test, $p<0.01)$. The modes of ALS30 pdf are about 2 and 6-8 days for the present and the future under the A2 scenario for both regions. Under the B 2 scenario, the modes of ALS30 are 2 and 6 days for the present and the future in the north;
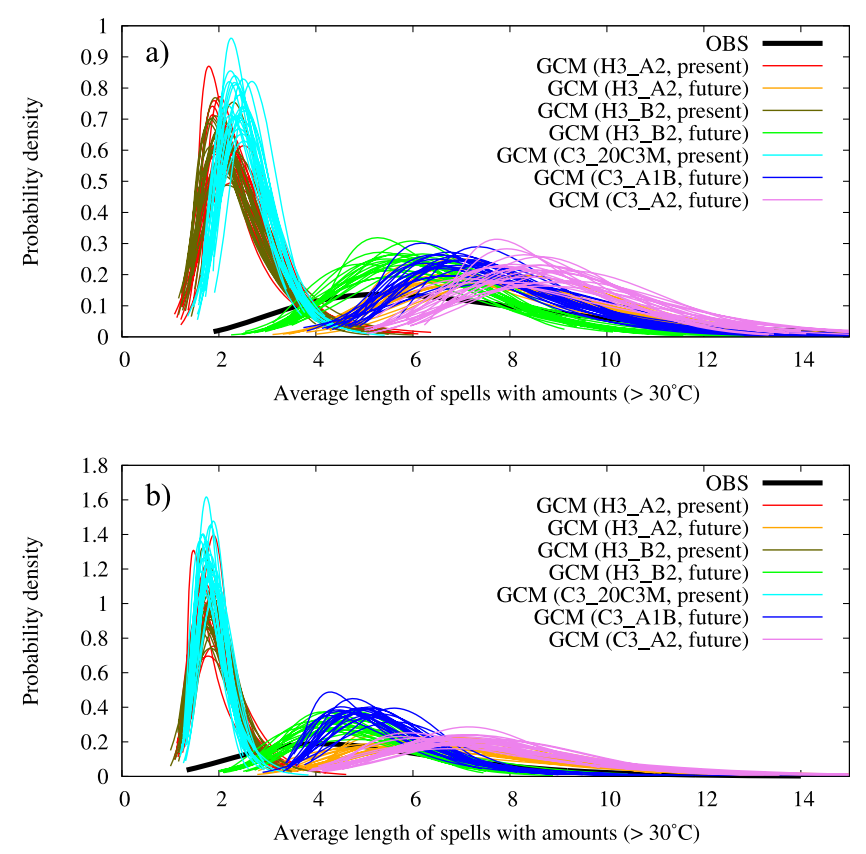

Figure 2. Log-normal (three-parameter) distribution of average length of spells with amounts more than $\mathrm{T}_{\max } 30^{\circ} \mathrm{C}$ between the present and future projections. (a) northern Shikoku region, (b) southern Shikoku region 

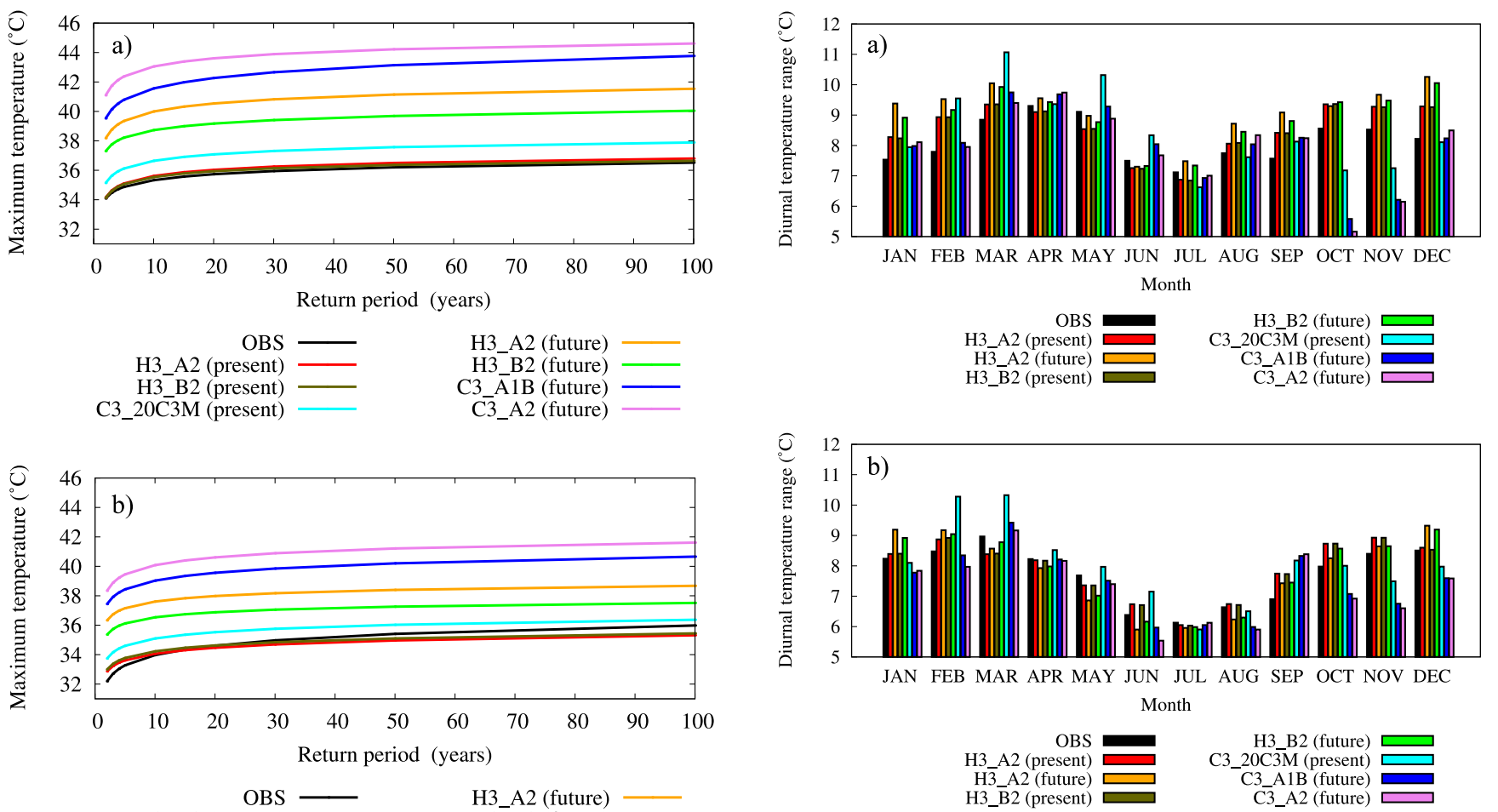

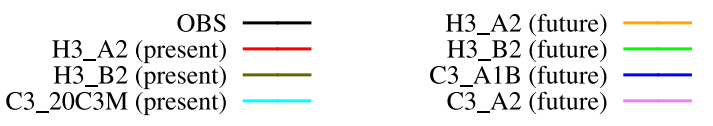

Figure 3. Extreme values by Log-normal (three-parameter) fit to observed and downscaled maximum daily temperature for the present and the future. (a) northern Shikoku region, (b) southern Shikoku region

while in the south, the modes are 2 and 4 days. Under the A1B scenario, modes in the future would be between the $\mathrm{A} 2$ and $\mathrm{B} 2$ scenarios. Compared to the northern region, the average changes in ALS30 were smaller in the south. In addition, average changes in ALS30 under the B2 scenario were small as compared to the A2 scenario for both GCM models.

$\mathrm{T}_{\text {max }}$ frequency analysis based on the downscaled data in the Shikoku region is shown in Figure 3. In this figure, the log-normal $(3 \mathrm{P})$ distribution-estimated $\mathrm{T}_{\max }$ are plotted for the studied return periods obtained using the observed and the future data (1961-1990, 2071-2099), and the SDSMdownscaled data. As shown in Figure 3, downscaled data for the future clearly show a significant increase in both the frequency and intensity of future extreme temperature events under both scenarios ( $\mathrm{t}$-test, $p<0.01)$. In the northern region, the extreme $\mathrm{T}_{\max }$ having 100 -year return period will be $40.0^{\circ} \mathrm{C}$ under the $\mathrm{B} 2$ scenario, while it will be $43.7^{\circ} \mathrm{C}$ for the case of the A1B scenario. Under the A2 scenario, the extreme $\mathrm{T}_{\max }$ for the HadCM3 and CGCM3 will be $41.5^{\circ} \mathrm{C}$ and $44.6^{\circ} \mathrm{C}$, respectively. In the southern region, the extreme $\mathrm{T}_{\max }$ will be $37.5^{\circ} \mathrm{C}$ under the $\mathrm{B} 2$ scenario, while it will be $40.6^{\circ} \mathrm{C}$ in the case of A1B scenario. Under the A2 scenario, the extreme $\mathrm{T}_{\max }$ for the HadCM3 and CGCM3 will be $38.7^{\circ} \mathrm{C}$ and $41.6^{\circ} \mathrm{C}$, respectively. The log-normal (3P) estimated on the basis of SDSM-downscaled data suggests a $40^{\circ} \mathrm{C}$ or a greater increase in the magnitude of a low-return period $\mathrm{T}_{\max }$ event under the $\mathrm{A} 1 \mathrm{~B}$ and $\mathrm{A} 2$ scenario for CGCM3 (Figure 3a).
Figure 4. Diurnal temperature range comparison between the present and future projections. (a) northern Shikoku region, (b) southern Shikoku region

Figure 4 shows the mean projected change in DTR for each month. In the northern Shikoku region, the average changes of DTR increased since average changes in $T_{\max }$ were larger than associated changes in $\mathrm{T}_{\min }$ for every month under both scenarios by HadCM3, except for CGCM3. In addition, from June to August, which is an important period for rice because this period includes the flowering and maturity dates, DTR changes using HadCM3 were positive from $0.44^{\circ} \mathrm{C}$ in $\mathrm{A} 2$, and $0.32^{\circ} \mathrm{C}$ in $\mathrm{B} 2$. Also, DTR changes using CGCM3 were positive from 0.13 in $\mathrm{A} 2$, and 0.15 in A1B. From June to August in the southern Shikoku region, DTR changes using HadCM3 were negative from $0.48^{\circ} \mathrm{C}$ in $\mathrm{A} 2$, and $0.33^{\circ} \mathrm{C}$ in $\mathrm{B} 2$. Also, the changes using CGCM3 were negative from 0.52 in $\mathrm{A} 2$, and 0.69 in $\mathrm{A} 1 \mathrm{~B}$.

\section{DISCUSSION}

\section{Future temperature signals}

The distribution-estimated magnitudes of temperature for studied return periods suggest that there is a possibility of serious damage to crop productivity due to increasing ALS30 and $T_{\max }$ in the future, due to reduced rice quality caused by high temperatures $\left(>30^{\circ} \mathrm{C}\right)$ (Kondo et al., 2005). The disparities between the two GCM models were generally not statistically significant (t-test, $p<0.01$ ). This result suggests that part of the difference between model uncertainties in extreme values may be related to handling solar forcing and radiation fluxes, and there is a need to clearly understand these phenomena through a further study.

On a global scale, previous modeling results suggest a 
trend towards a reduction in DTR, except for the United States and Western Europe from June to August (Dai et al., 2001; Stone and Weaver, 2003; Lobell et al., 2007), while IPCC indicated that projected changes in DTR over Asia are negative in summer, using AOGCM simulations with increasing concentrations of greenhouse gases and sulfate aerosols in the atmosphere. As mentioned in the introduction, the agricultural and hydrological impacts are cases where $\mathrm{T}_{\text {max }}$ and DTR changes may be very important, because changes in DTR have multiple possible causes (cloud cover, urban heat, land use change, aerosols, water vapor, and greenhouse gases) and biological and hydrological processes are differentially sensitive to daytime and nighttime conditions. In our study using a statistical downscaling model, it was found that future $\mathrm{T}_{\max }$ and DTR have the different tendency in northern and southern Shikoku region.

\section{Limitations and uncertainties related to the study}

Some potential errors and differences of the future warming from SDSM remain, as the regression-method is inherently conservative in the presence of non-stationarity of the cross-scale relationships in the climate system. These errors and differences could be mainly due to the chosen predictors. The relationship between the predictor and predictand is achieved by only considering the data statistical condition. The SDSM model does not take into consideration the physical process. In addition, the model is highly sensitive to the choice of predictor variables and empirical transfer scheme. Moreover, the location of regional grid points strongly influences the temperature simulated by GCMs. Therefore, strong biases are present in the temperature regime simulated by GCMs for the current climate over the Shikoku region. There is considerable variability and uncertainty in results on a regional scale, and climate change signals strongly vary between different GCMs (IPCC, 2001). The significant difference between NCEP and GCM predictors indicate that, even if the SDSM is calibrated well with the NCEP including predictors, it does not guarantee a comparable downscaling performance when we use the corresponding GCM predictors. However, a reasonable spatial projection of local climate change is produced for some interest areas for impact studies.

GCM models do not sample a wide range of uncertainty and are not distributed around the truth. Therefore, combining multi-model ensembles can help quantify uncertainties in future climate projections, through exploring and comparing structural characteristics of the models. This study points to the potential for empirical methods by demonstrating the convergence of different climate change projections at the local scale from different GCMs used as inputs to the SDSM process. Given that a model provides one possible climate behavior under the designed climate change scenario, it is desirable that several GCM or SDSM simulation outputs are produced and compared to achieve greater confidence in extreme event analysis for temperature. Taking the uncertainty in the impact of future climate impact into consideration, the effects of future climate on agriculture need to be further studied.

\section{CONCLUSIONS}

The objective of this study was to downscale large-scale atmospheric variables from GCM outputs to produce climate variables at a regional- and local-scale, to apply SDSM method to GCM data over the Shikoku region. According to the results, the main conclusions are as follows:

1. The average length of spells with amounts greater than $\mathrm{T}_{\max } 30^{\circ} \mathrm{C}$ for the present and the future increased significantly for CGCM3 and HadCM3. The ratio of ALS30 increase is the largest for the A2 scenario. Additionally, the increasing rate in the northern Shikoku region is larger than in the southern Shikoku region.

2. The distribution of $\mathrm{T}_{\max }$ for the 100-year return period was obtained. The downscaled data for the future clearly showed a significant increase in both the frequency and intensity for future extreme events of temperature under both scenarios. In particular, a future 100-year return period event will be around 2 (H3_B2, southern) to $7^{\circ} \mathrm{C}$ (C3_A2, northern) higher than that of the present-day 100-year return period event.

3. Downscaling is able to capture the systematically higher climate warming corresponding to the A2 scenario as compared to the B2 emission scenario. From June to August, the average DTR changes using HadCM3 and CGCM3 were negative in the southern Shikoku region and were positive in the northern Shikoku region under $\mathrm{A} 2$, A1B, and B2 scenarios.

Future works to evaluate the performance of the statistical and dynamical downscaling models in simulating past changes, $\mathrm{T}_{\text {max }}$ and DTR would be useful for further constraining uncertainty in future projections.

\section{SUPPLEMENTS}

Supplement Figure S1. The SDSM downscaling process and the generation of the daily synthetic weather time series based on two GCM models

Supplement Figure S2. $R^{2}$ and SE between the observed and simulated results for the calibration period (1961-1990)

Supplement Figure S3. Comparison of the observed and SDSM-estimated maximum and minimum temperature for the validation periods (1991-2000) ((a) $\mathrm{T}_{\max }$, north, (b) $\mathrm{T}_{\text {min }}$, north, (c) $\mathrm{T}_{\text {max }}$, south, (d) $\mathrm{T}_{\text {min }}$, south)

Supplement Figure S4. Comparison of the observed and SDSM-estimated ALS30 for the validation periods (19912000) ((a) north, (b) south)

Supplement Figure S5. Time series of observed (SDP) and simulated (NCEP) daily maximum and minimum temperature for 1961-1971 ((a) $\mathrm{T}_{\max }$, north, (b) $\mathrm{T}_{\min }$, north, (c) $\mathrm{T}_{\max }$ south, (d) $\mathrm{T}_{\min }$, south)

Supplement Figure S6. Time series of simulated (HadCM3 and CGCM3) daily maximum and minimum temperature for 1961-1971 and 2071-2081 ((a) $\mathrm{T}_{\max }$, HadCM3, north (b) $\mathrm{T}_{\max }$, CGCM3, north, (c) $\mathrm{T}_{\min }$, HadCM3, north, (d) $\mathrm{T}_{\text {min }}$, CGCM3, north, (e) $\mathrm{T}_{\max }, \mathrm{HadCM}_{3}$, south (f) $\mathrm{T}_{\max }$, CGCM3, south, (g) $\mathrm{T}_{\text {min }}$, HadCM3, south, (h) $\mathrm{T}_{\text {min }}$, CGCM3, south)

Supplement Table SI. Summary of predictors in NCEP reanalysis (the one in bold text was selected for model calibration) 
Supplement Table SII. The coordinates of each station and value in each grid box correspond to the value over the center of the cell defined over an area (CGCM3: $3.75^{\circ}$ longitude and $3.75^{\circ}$ latitude, HadCM3: $3.75^{\circ}$ longitude and $2.5^{\circ}$ latitude)

\section{REFERENCES}

Chen YD, Chen X, Xu CY, Shao Q. 2006. Downscaling of daily precipitation with a stochastic weather generator for the subtropical region in South China. Hydrology and Earth System Sciences Discuss 3: 1145-1183. doi: 10.5194/hessd3-1145-2006.

DAI CGCM3 Predictors. 2008. Sets of Predictor Variables Derived from CGCM3 T47 and NCEP/NCAR Reanalysis. Version 1.1, April 2008, Montreal, QC, Canada, 1-16.

Dai A, Wigley TML, Boville BA, Kiehl JT, Buja LE. 2001. Climates of the twentieth and twenty-first centuries simulated by the NCAR climate system model. Journal of Climate 14: 485-519. doi: 10.1175/1520-0442(2001)014<0485:COTTAT $>2.0 . \mathrm{CO} ; 2$.

Dhakhwa GB, Campbell CL. 1998. Potential effects of differential day-night warming in global climate change on crop production. Climate Change 40: 647-667. doi: 10.1023/ A:1005339800665.

Easterling DR, Meehl GA, Parmesan C, Changnon SA, Karl TR, Mearns LO. 2000. Climate extremes: observations, modeling, and impacts. Science 289: 2068-2074. doi: 10.1126/ science.289.5487.2068.

Gordon C, Cooper C, Senior CA, Banks H, Gregory JM, Johns TC, Mitchell JFB, Wood RA. 2000. The simulation of SST, sea ice extents and ocean heat transports in a version of the Hadley Centre coupled model without flux adjustments. Climate Dynamics 16: 147-168. doi: 10.1007/ s003820050010.

Hashmi MZ, Shamseldin AY, Melville BW. 2011. Comparison of SDSM and LARS-WG for simulation and downscaling of extreme precipitation events in a watershed. Stochastic Environmental Research and Risk Assessment 25: 475-484. doi: 10.1007/s00477-010-0416-x.

He B, Takara K, Yamashiki Y, Kobayashi K, Luo P. 2011. Statistical analysis of present and future river water temperature in cold regions using downscaled GCMs data. Annuals of Disaster Prevention Research Institute 54B: 103-110.

Hegerl GC, Zwiers FW, Scott PA, Kharin VV. 2004. Detectability of anthropogenic changes in annual temperature and precipitation extremes. Journal of Climate 17: 3683-3700. doi: 10.1175/1520-0442(2004)017<3683:DOACIA>2.0.CO;2.

Huang J, Zhang J, Zhang Z, Xu CY, Wang B, Yao J. 2011. Estimation of future precipitation change in the Yangtze River basin by using statistical downscaling method. Stochastic Environmental Research and Risk Assessment 25: 781-792. doi: 10.1007/s00477-010-0441-9.

Iizumi T, Takayabu I, Dairaku K, Kusaka H, Nishimori M, Sakurai G, Ishizaki NN, Adachi SA, Semenov MA. 2012. Future change of daily precipitation indices in Japan: A stochastic weather generator-based bootstrap approach to provide probabilistic climate information. Journal of Geophysical Research: Atmospheres 117: doi: 10.1029/2011JD017197.

IPCC. 2001. Climate Change 2001: The Scientific Basis. Contribution of Working Group I to the Third Assessment Report of the Intergovernmental Panel on Climate Change. Cambridge University Press, Cambridge, UK and New York, USA, $881 \mathrm{pp}$.
IPCC. 2007. Climate Change 2007: The physical science basis. Contribution of Working Group I to the Fourth Assessment Report of the Intergovernmental Panel on Climate Change. Cambridge University Press, Cambridge, UK and New York, USA, $966 \mathrm{pp}$.

Kondo M, Ishimaru T, Sanoh Y, Umemoto T. 2005. Research directions on grain ripening under high temperature in rice. Journal of Agricultural Science 60: 462-470 (in Japanese).

Lobell DB, Bonfils C, Duffy PB. 2007. Climate change uncertainty for daily minimum and maximum temperatures: A model inter-comparison. Geophysical Research Letters 34: L05715, 1-5. doi: 10.1029/2006GL028726.

Masutomi Y, Takahashi K, Harasawa H, Matsuoka Y. 2009. Impact assessment of climate change on rice production in Asia in comprehensive consideration of process/parameter uncertainty in general circulation models. Agriculture, Ecosystems and Environment 131: 281-291. doi: 10.1016/j.agee.2009.02.004.

Nagata K, Takita T, Yoshinaga S, Terashima K, Fukuda A. 2004. Effect of air temperature during the early grain-filling stage on grain fissuring in rice. Japanese Journal of Crop Science 73: 336-342.

Pope VD, Gallani ML, Rowntree PR, Stratton RA. 2000. The impact of new physical parameterizations in the Hadley Centre climate model: HadAM3. Climate Dynamics 16: 123146. doi: $10.1007 / \mathrm{s} 003820050009$.

Saito K, Fujita T, Yamada Y, Ishida J, Kumagai Y, Aranami K, Ohmori S, Nagasawa R, Kumagai S, Muroi C, Kato T, Eito H, Yamazaki Y. 2006. The operational JMA nonhydrostatic mesoscale model. Monthly Weather Review 134: 1266-1298. doi: $10.1175 / \mathrm{mwr} 3120.1$.

Skamarock WC, Klemp JB, Dudhia J, Gill DO, Barker DM, Wang W, Powers JG. 2005. A description of the Advanced Research WRF Version 2. NCAR Tech. Note/TN-468+STR, 88 pp.

Stone DA, Weaver AJ. 2003. Factors contributing to diurnal temperature range trends in twentieth and twenty-first century simulations of the CCCma coupled model. Climate Dynamics 20: 435-445. doi: 10.1007/s00382-002-0288-y.

Tan G, Shibasaki R. 2003. Global estimation of crop productivity and the impact of global warming by GIS and EPIC integration. Ecological Modelling 168: 357-370. doi: 10.1016/S0304-3800(03)00146-7.

Tatsumi K, Yamashiki Y, Silva RV, Takara K, Matsuoka Y, Takahashi K, Maruyama K, Kawahara N. 2011. Estimation of potential changes in cereals production under climate change scenarios. Hydrological Processes 25: 2715-2725. doi: 10.1002/hyp.8012.

Tatsumi K, Yamashiki Y. 2012. Sensitivity analyses of crop yields and changes in climate variables simulated with iGAEZ. Hydrological Processes 26: 2482-2500. doi: 10.1002/ hyp.9342.

Tebaldi CK, Hayhoe K, Arblaster JM, Meehl GA. 2006. Going to the extremes: An intercomparison of model-simulated historical and future changes in extreme events. Climate Change 79: 185-211. doi: 10.1007/s10584-006-9051-4.

Wilby RL, Dawson CW, Barrow EM. 2002. SDSM-A decision support tool for the assessment of regional climate change impacts. Environmental Modelling \& Software 17: 145-157. doi: 10.1016/S1364-8152(01)00060-3.

Wilby RL, Dawson CW. 2007. SDSM 4.2-A decision support tool for the assessment of regional climate change impacts. http://co-public.lboro.ac.uk/cocwd/SDSM/SDSMManual. pdf. Last access January 28, 2013.

Wilkens P, Singh U, White JW. 2001. A code-level analysis for temperature effects in the CERES models. Modeling Temperature Response in Wheat and Maize, Proceedings of a Workshop, 1-7. 